\title{
MASTER OF PHOTOGRAPHY
}

\section{INVESTIGATING TRANSNATIONAL CREATIVE EXCHANGES IN THE PRODUCTION OF A READY- MADE TALENT SHOW}

\author{
Marta Perrotta \\ Università Roma Tre \\ marta.perrotta@uniroma3.it
}

\begin{abstract}
Italy plays a peripheral role in the global market of ready-made shows, for historical reasons that pertain both to the marginality of the Italian language and to the scarcity of cultural and economic investments in the globalization of its products. This essay focuses on the analysis of Master of Photography, a talent show produced since 2015 by the Italian indie B/Arts for the pan-European production hub that Sky Limited conceived to produce suitable content for the group's national art channels (UK, Ireland, Germany, Austria and Italy). By situating this research within media production studies, the article will focus on the creative and production work needed to create and circulate a talent competition on art photography, a TV show belonging to a genre which usually licenses and exports formats adaptable to each country. The main outcomes highlight interesting forms of creative negotiation between two of the three main components of the coproduction, with results that push the show towards a broadening of the horizons of a now classic television genre.
\end{abstract}

Keywords: format, canned show, art television, co-production, pan-European, talent show, documentary

\section{No Country for TV Export. The Uncomfortable Role of Italy in the Transnational TV Market}

In the global panorama of the TV industry, Italy plays a peripheral, problematic role both in terms of the production and international licensing of products - documentaries, series - and of the distribution of original formats to be adapted. Already in 2009, the FRAPA TV Formats of the World report defined Italy as a "sleeping giant" in the global TV market, ${ }^{1}$ and in 2016 an Italian study conducted for the APT (Association of Television Producers) ${ }^{2}$ highlighted the country's limited ability to develop an international-level TV creativity, despite the presence of transnational interests at different structural levels in the industry. ${ }^{3}$

Even more than linguistic and creative, this marginality is, above all, cultural and economic. The creators do not invest in the globalization of their products, deeming the national market safer - this choice is often inevitable - than the international one. This pushes the development of entertainment modes which rely on non-exportable elements (such as, personalities and talent) rather than "formattable elements (the shows' mechanisms)" 4 wich could take the programs outside national borders. Besides emphasizing public television's missed opportunities to serve as "the driving force of the entire country's production apparatus", ${ }^{5}$ research has pointed out a substantial lack of structural policies supporting a globally conceived TV content, the absence of "professional figures who could garrison the international market", ${ }^{6}$ and, at the same time, the inability on the part of producers and especially broadcasters to act in synergy, in searching for advantageous protocols regarding international exploitation rights. 
It is not a coincidence that Jan Salling, FRAPA's co-chairman and format distribution consultant, defines Italy and other Southern European countries such as Spain and Greece 'chickenshit' countries: not only "do they export almost no new ideas, but are not even first movers. They don't buy anything that hasn't already been sold in at least ten countries. [...] If you're not a first mover, it's hard to become a creative hotspot". ${ }^{7}$ The lack of international innovation is a problem that can be handled only by those who take on the risk of investing in new projects and choosing the unbeaten path.

In this essay, I aim to problematize this issue by analyzing a TV show that, in Italy, appears as unique and innovative under many respects. It originated from the creative coproduction of three European countries (Italy, the United Kingdom, and Germany), and was broadcast as a ready-made product on these countries' Sky Arts channels, as well as in Ireland and Austria. The show was also sold in several other markets, but is still marked by strong Italian production roots, thanks to the work of Ballandi Arts (B/Arts, today a part of Ballandi) ${ }^{8}$ on behalf of the pan-European Sky Arts Production Hub (SAPH). ${ }^{9}$

The show is neither a documentary nor a drama series - two genres that are "the new normal" 10 for international coproduction and ready-made distribution - but rather a photography talent show meaningfully entitled Master of Photography (hereafter, MoP). The title is evidently inspired by the most successful of cooking show formats: in this show, a panel of expert judges selects the best among a group of photographers, both professional and amateur.

By locating this research study under the heading of media production studies, I will focus on the creative and production work needed to create and circulate a TV show belonging to a genre which usually licenses and exports formats adaptable to each country.

\section{Literature Review and Research Questions}

So far, the studies that have examined the television flows between the local and the global have given great importance to analyzing the format system, ${ }^{11}$ one which, though nearing the latter part of its industrial life cycle,$^{12}$ is still an essential part of the TV business and provides a vantage point on the relationship between different production cultures, local adaptations, and national identities.

This research highlights the complex relationship between the features of a given media system - with its broadcasters, its market dynamics, its specific programming politics - and the socio-cultural, mindset, as well as the differences in perception between one country and the other. ${ }^{13}$ Once combined, these elements often produce substantially different results in format adaptations. That is why studies of formats have focused mainly on their localization in different contexts, in the dialectic between homologation on universal modes encouraged by the globalization of the TV industry, and local spaces of cultural heterogeneity, in terms of content and production modes. Among the most studied cases, there are examples of observational reality programmes, game shows and talent competitions like Survivor, ${ }^{14}$ Big Brother, ${ }^{15}$ Who Wants to Be a Millionaire?, ${ }^{16}$ Pop $/ d o /{ }^{17}$ and Masterchef,${ }^{18}$ as well as some scripted formats like Ugly Betty. ${ }^{19}$

Within a debate that was previously dominated by a dialectic between cultural imperialism and local identities, the theme of transnational television has recently emerged. This lens brings emphasis towards the "intensification of connections between national industries and multinational conglomerations", ${ }^{20}$ and the numerous forms of cross-border exchanges of "TV programmes but also knowledge, practices, creative ideas, financial means and personnel" - of which the formats are the most important demonstrations. 
At the same time, a considerable part of transnational television - which has received lesser attention, in favour of the format phenomenon - is made up of often coproduced ready-made products meant for international distribution, like dramas and documentaries. This area of investigation has existed since television itself and, as the study by Nordenstreng and Varis has pointed out, ${ }^{21}$ has been dominated by the focus on the United States and their exportations, later complemented by the attention on the emergence of other select production centres such as Australia, Mexico, Brazil, Japan, and few European countries, ${ }^{22}$ always keeping an eye on potential cultural imbalances and the risk of homogenization among countries.

But, even if research on the global import-export of TV shows is less up-to-date and articulate, it has nonetheless been prompted by two interdependent factors. First, the role played by "non-traditional distribution over digital platforms", which, as Hilmes remarks, directed the attention of audiences and scholars (especially in the US and UK) to serial products all over the world: "programs in their original forms, complete with subtitles", which in the past would have been 're-versioned' or simply not considered for programming. ${ }^{23}$ The second factor is the international success of Nordic Noir in the form of Scandinavian crime series, and above all the Danish Forbrydelsen (The Killing, 2007-2012), which demonstrated the potential of local products distributed abroad, as well as its strength facing adaptations: ${ }^{24}$ "The Nordic Noir success of the past years has shown that audiences can gradually grow accustomed to watching foreign fare on national screens and that part of the fascination of these series can be the "exotic" element of learning more about another country and culture". ${ }^{25}$

This success has encouraged scholars to reflect upon transnational production modalities, with nationally-grounded productions consequently re-considered in global terms:

$[T]$ ransnational coproduction in the current era includes not just cofinancing or presale of distribution rights (i.e., putting money into a series upfront, but contributing very little creatively to the production): it also involves a creative partnership in which national interests must be combined and reconciled, differing audience tastes considered and, often, the collision of public-service goals with commercial expectations negotiated. ${ }^{26}$

Although Hilmes analyses the evolution of production partnerships between the US and UK in the field of serial fiction, I am interested in applying her research questions to creative coproduction in the case study that I propose.

The MoP experiment is an artistic skill competition belonging to the talent show genre, which in turn belongs to the wider category of reality entertainment. As the numerous local versions of $I d o l$ and Masterchef show, it is very rare that a product of this kind is proposed as ready-made to different national publics: it is easier and more effective to localize it through characters, stories, language, and cultural traits. From an empirical viewpoint, this study integrates different qualitative methodologies, conducting a formal analysis of $M o P$ through the identification of its narrative structures and the highlighting of its most salient stylistic aspects. In addition to this, I have conducted semi-structured interviews with professionals involved in different sectors of the show's Italian production, from key executives to authors and producers. Through the critical analysis of MoP's form, and the contextualization of its style within the structural conditions of its production, my study looks at the writing, creative, and managerial processes that allow for the making of this product, focusing on the delicate issue of creative control.

In what way do international partners manage the creative process and negotiate between the need for national specificity and the necessity of a global appeal? How was the narrative engine assembled for a show that shares the same traits as several other international formats - the tasks, the expert judges, the aesthetic evaluation, the prize money - and yet not be customized and domesticated for different local versions but rather sold as ready-made? What are the challenges of a skill competition conceived for an international public? 


\section{The Challenges of a Ready-Made Talent Show}

Ballandi is a leading production company in the field of entertainment in Italy. It was founded by one of the most important Italian producers, Bibi Ballandi - who passed away in 2018 - a man that made several television hits of the last decades, including Ballando con le stelle, 2005-, (the Italian adaptation of Strictly Come Dancing, 2004- ), which reached its $14^{\text {th }}$ edition in 2019. With the launch of the Italian channel Sky Arte (2012), Ballandi has developed more than 100 hours of original productions about fine arts filmed in English and with a foreign-friendly style, filling the channel's schedule with many titles: Masterpieces Unveiled (2013-), a series looking for secret or unconventional messages in the works of great masters, hosted by the actress Greta Scacchi; Seven Wonders (2013-), a documentary series that presents innovative views of Italian landmarks (with an early use of flying drones); Artists in Love (2016), a docu-series that looks at love affairs between painters, musicians, writers and film directors and their muses; Mystery of the Lost Paintings (2018-), a seven-episode documentary on masterpieces that were destroyed, stolen or lost during the $20^{\text {th }}$ century; and above all the award-winning ${ }^{27}$ talent show MoP (2016-), now in its fourth season.

$M o P$ can be seen as a pivotal case in the evolution of Italian production routines, given the complexities and challenges presented by the creative coproduction (Italy, UK, and Germany) which was managed by SAPH. MoP brings together two TV narrative modes which are usually polar opposites: it is both a contest among photographers and a documentary that allows the public to view the whole process behind the making of a picture. It is also a way for the contestants to narrate the very reality that they need to document. This is possibly the first of the show's many unique elements which I aim to point out.

The mechanism of MoP, however, is far from original, and it demonstrates - already answering one of my research questions, at least partially - that its narrative engine is not any different from that of many other locally adapted talent shows. A group of photographers with varying backgrounds and skill levels, compete for a significant money prize. ${ }^{28}$ The contest involves tasks where the photographers are required to work with different genres, from studio portraits to street photography, from reportage to nudes, from animal pictures to archaeological landscape, dealing with subjects that can be either picked or assigned. The editing of photos is supported by a professional who changes every time, ${ }^{29}$ but the last word pertains to a jury that is made up of three internationally renowned personalities in the photography world: the innovative but controversial Italian photographer Oliviero Toscani, the British curator and cultural historian Mark Sealy, and visual editor Elisabeth Biondi, who was born in Germany. ${ }^{30}$ The jury is tasked with making the contest progress by eliminating one contestant after another, until a winner is designated.

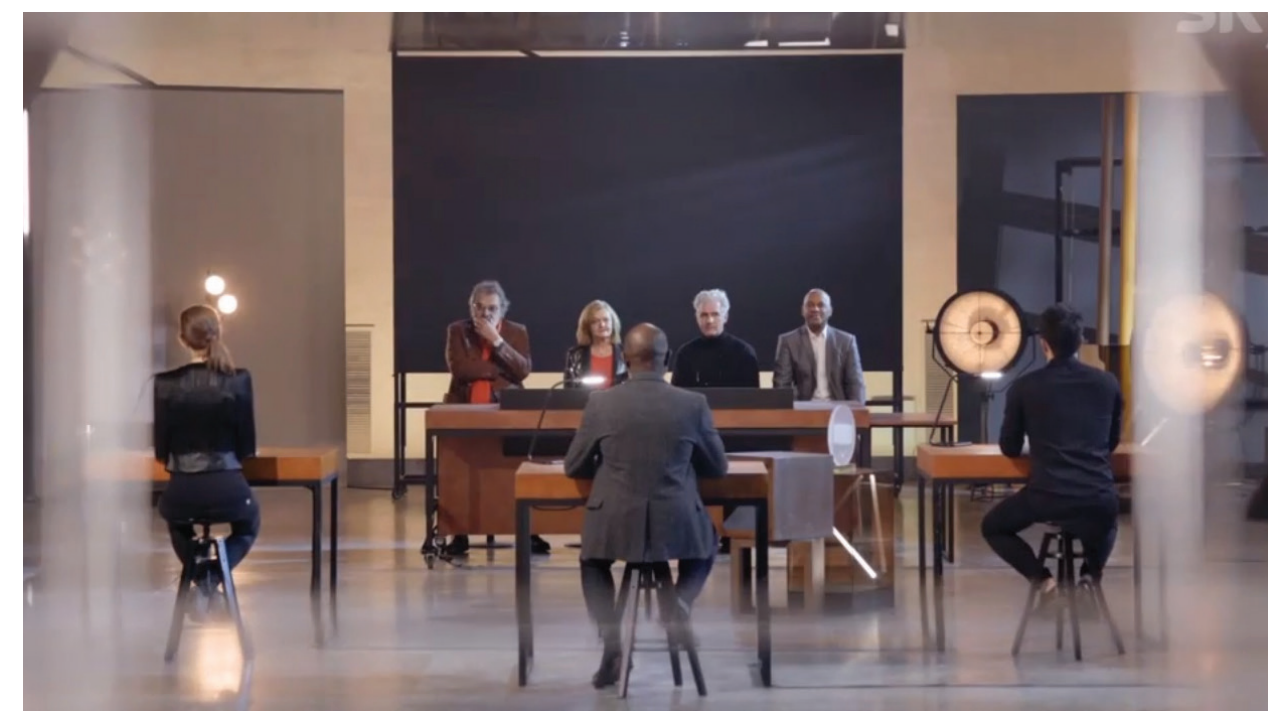

Figure 1. Frame from episode 'Sanctuary,' 3: 8. 
The format of MoP originates from the collaboration of three people, two of whom are connected to Sky: Roberto Pisoni, head of Sky Arte Italia and SAPH, and Barbara Frigerio, showrunner and editorial responsible for SAPH, and therefore the link with the other countries that broadcast the show. The third person is Mario Paloschi, CEO of B/Arts, who was in charge of the executive production from the very first steps in the editorial development of the original idea. This creative core lay the foundations of the show's identity, and they have the final word anytime that issues regarding aesthetics, style, and content needed to be settled.

The genesis of the format coincides with the birth of SAPH in 2015 and with Sky Limited's idea to produce suitable content for any national art channel. Technically, MoP is not a coproduction that uses the three countries' resources, but rather a specific, experimental budget which 'is registered in Italy, where the Hub is located, but is licensed by the mother-company in the UK. Naturally, for fiscal reasons, there is a framework agreement in place, as well as a licensing contract which allows us to distribute the show to the other countries' channels. It would be too complicated to have three different budgets, as is the case in coproductions. It is, rather, a creative coproduction'. ${ }^{31}$ This presents very interesting aspects in terms of the collaboration among subjects:

[E]ach country has its own television taste. Putting together all of these tastes and creating something that everyone likes, or that at least the commissioning editors of the three Sky Arts channels like, that was a real challenge. One that, as far as I know, had never been tried before. ${ }^{32}$

$M o P$ is, therefore, the first project by SAPH to be conceived for a transnational public, along with two other documentary series (Italian Season and Artists in Love, also produced by B/Arts): "it was the most daring experiment, aiming to propose something that did not exist (a photography talent show) and in a previously untested way: a pan-European, ${ }^{33}$ or even 'stateless' format". ${ }^{34}$

Photography is both a noble art and a widespread practice. The difference in choosing this, rather than cooking or dance, as the main theme in a TV talent game, lies in the extreme popularization and disintermediation of judgment, which can vary based on the aesthetic sensitivity and the background of the viewer, but that is still immediate and possible for the naked eye, with no need of an expert to, for instance, taste a dish and give their opinion. This aspect, too, is to be regarded as a unique element, one that possibly allows the show to go beyond local borders and cultural specificities.

At the same time, the format wishes to speak to the Sky Arte public, a world made up of art lovers: these are people who go to exhibitions, who read more than six books a year, who have a high income and advanced education. For this very selective (and restricted) public, the formula devised by Sky Arte Italia, for instance, plays on the difficult balance between cultural investigation and popularization, ${ }^{35}$ that conjugates dense cultural contents with the language of mainstream television in an experimental way. ${ }^{36}$

The format presents a classical structure with horizontal narrative lines which run through the whole series, and a vertical narrative for each episode, which is always divided into two equal parts: one that takes place on location presenting the task, the other in the studio, featuring the photographs and the jury's evaluation. Within the frame of the talent show, emphasis has been placed on photographic technique, highlighting details without making it too hard for the public who may not know what a shutter is. The photograph is shown through a still frame, with graphics describing its main features (iris opening, exposure time, iso, focal length), while the editing showcases the moments in which the contestants verbalise, also on a technical level, their creative processes. The same is asked of the judges who, in their evaluation, are required constantly to explain technical elements employed in their aesthetic judgments, with the aim of making expert opinions entirely accessible and providing the audience the tools to develop an aesthetic competence in photography. 

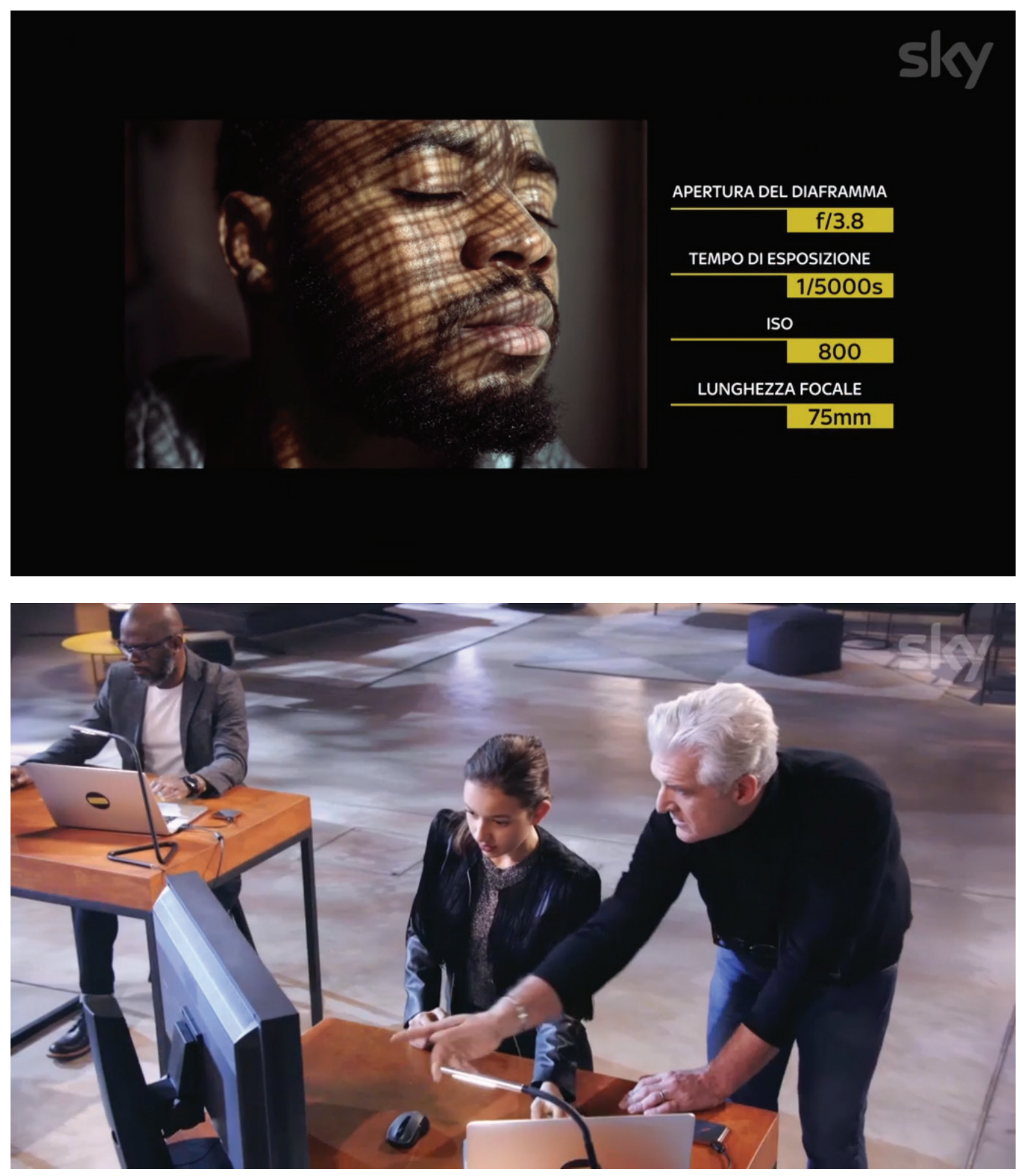

Figures 2, 3. Frames from episode 'Sanctuary,' 3: 8. 
MoP is unique also because it is a talent show with no performance. There are no songs or dances, no moments in which the artists express themselves before the judges. During the episode's task, the contestants take hundreds of pictures, but when the time comes to present them, they need to select, depending on the task, from one to a maximum of five images for the judges to evaluate. Only at this stage (or after) can the video recording of the moments when the pictures were taken be viewed (provided it was caught on camera).

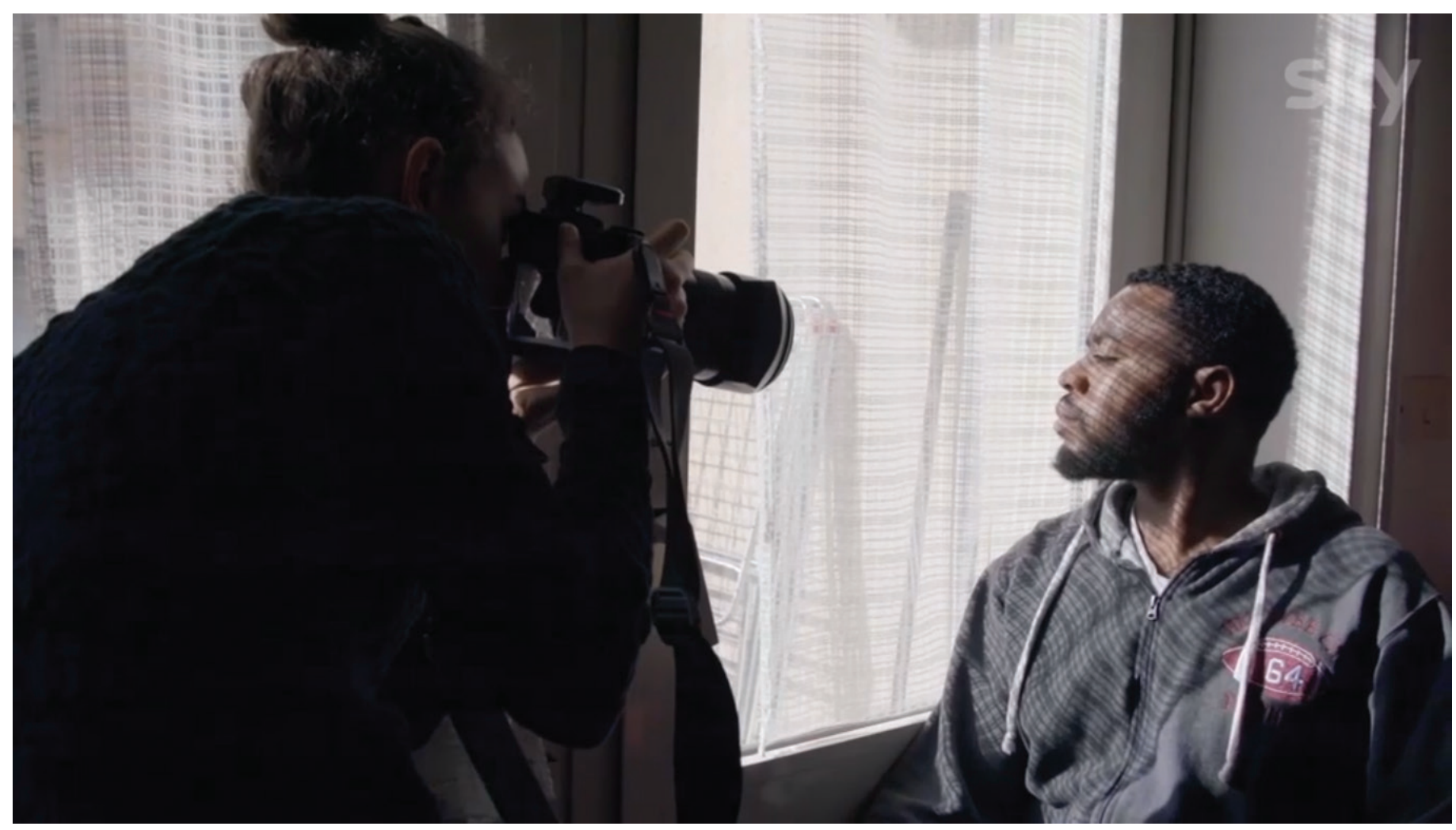

Figure 4. Frame from episode 'Sanctuary,' 3: 8.

From a production standpoint, reconstructing the narrative of those instants requires hours of filming (for a 45-minute episode, more than 70 hours are filmed, multi-camera):

[T]his means having a camera, a mic, and a logger-author on each contestant asking them what they are doing, so that sometimes we also get a contestant who turns around and replies 'I'm trying to frame that window over there, waiting for a change in light which might create a nice effect'. The problem is, you can't do this for every shot. ${ }^{37}$

This limitation becomes an opportunity, and each photograph shown is told through the reconstruction of the thoughts and feelings of the person who took it, keeping in mind that we are dealing with a very peculiar human material: contestants that tend to 'snub TV even though, like everyone else on talent shows, they are motivated by vanity'. ${ }^{38}$ Besides, the artistic component of the tasks makes it very hard to manage contestants in the perspective of narrative: 
The art that the photographers need to express cannot be directed by the authors. What the reporters do is make sure that all the material which will potentially constitute the vertical line and will give elements to the horizontal one was filmed. ${ }^{39}$

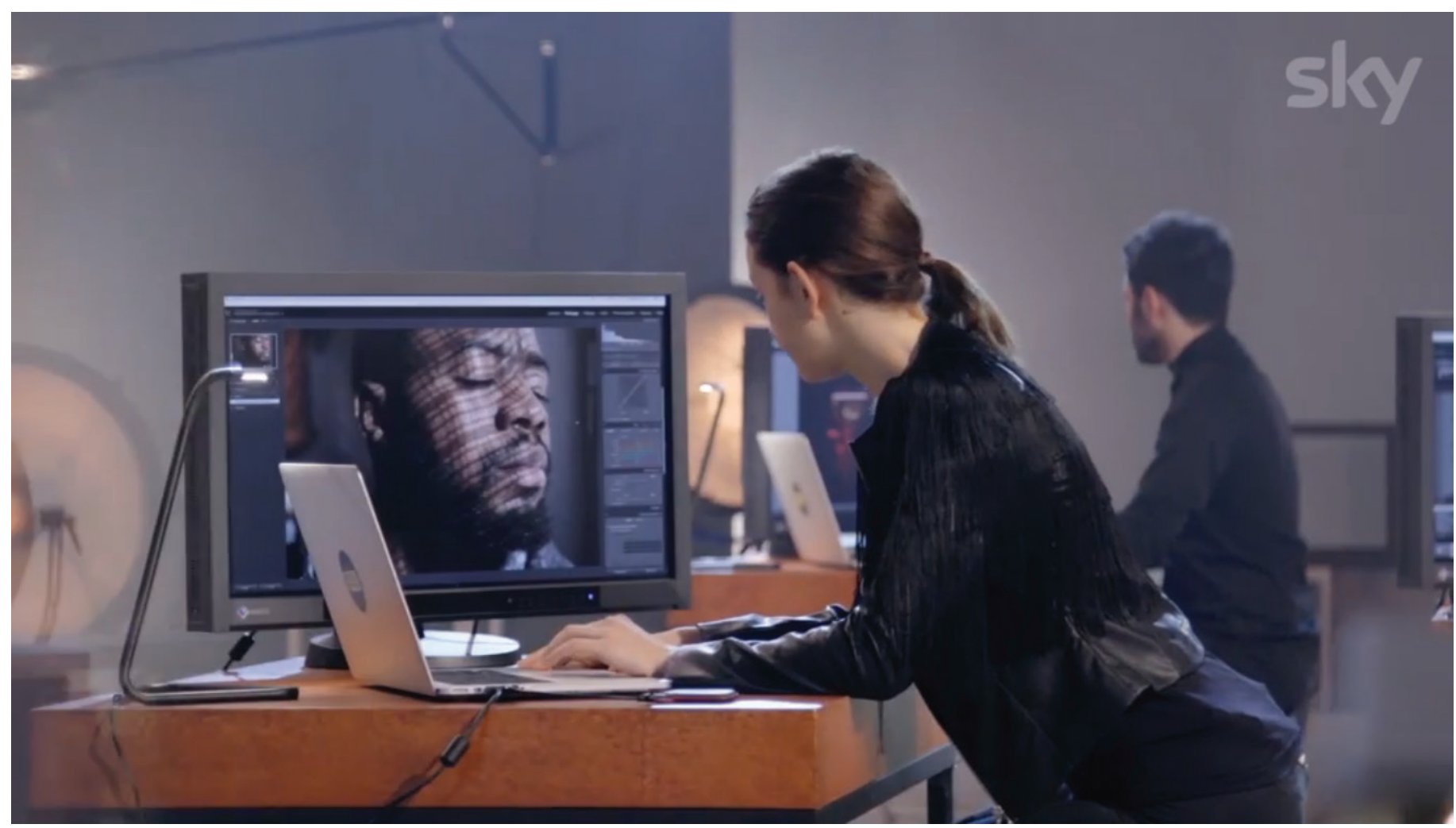

Figure 5. Frame from episode 'Sanctuary,' 3: 8.

This is an innovative element in the genre's language, one afforded by the singularity of the subject of the skill competition: it requires an approach that reduces the sensationalism of talent shows through the analytical tools of documentaries. "The dynamics of photography", Barbara Frigerio remarks, "is very solitary. The contestants interact very little, and even their exchanges with the judges are short and emotionally neutral. We focus more on the photo and on the photographer's activity, leaving aside the details of his feelings". ${ }^{40}$ The contestants' identities, their nationalities, their emotions, and their competitiveness are almost cancelled, while the creative process, with its intimate, poetic nature, are emphasized.

\section{Anatomy of a Production Process}

In its first season, at least, the format suffered from necessary fine-tuning between creative and production agents. Specifically, the first problem for the CEO of B/Arts was to hire a team of Italian people who were fluent in English: "It took us three years and numerous productions, but in the end the team was 'distilled', leaving only the people suited for the job, either for linguistic or methodological reasons". ${ }^{41}$ The definition of work methodology in an international coproduction is the first complex decision-making process encountered: 
It is a constant reporting. When you have each country's commissioning editor seated at one table, every step needs to be clear to each involved party, that is, over one hundred people in five countries. Deciding upon the most efficient file storage order in the cloud - from script to direction and production notes, each with its modifications and respective people in charge - took us six months. ${ }^{42}$

The complexity is proportional to the aptitude to this modus operandi:

Forcing Italians to adopt this mindset was a difficult job, because no one in Italy teaches it to those who enter the professional world. It was very tough, a real process. Now we can do it, but we only do it in international productions, because we have to. This has not taken root in our Italian productions. ${ }^{43}$

This latter aspect of the work's organization highlights elements that, by contrast, pertain to the productive relationships with Italian broadcasters, with which negotiations take place in informal contexts ("with RAI, it's about sensations", Paloschi says) or, as Scaglioni remarks, according to "less than transparent procedures". ${ }^{44}$ The volatile relationship between buyers and producers is also mirrored in the creative room:

[In Italy] we are not used to dissecting the creative process to such a degree. Often, it is all kept in the minds of authors and directors, who are there, see each other, and talk. No one ever writes anything until they are forced to, because a schedule needs to be prepared for recording. ${ }^{45}$

All the interviewees highlight the complicated sequence of approval steps at every level of the production chain, from concept development to the selection of artists and contestants, from the treatment to the episode scripts and all editing phases:

We've had to introduce a preview even before the rough cut, so as to anticipate potential structural changes without then having to upset the editing once the work was finalized on a semantic and conceptual level. Each phase - rough cut, fine cut, pic lock - needs triple approval. It's a constant debate. ${ }^{46}$

A substantial agreement emerges from the sample of interviewees regarding their views on the experience of mediation among the different national components:

There is a bizarre decisional democracy which is sometimes positive and sometimes not, because it is influenced by the time variable. We need a lot of time in order to find a formula that works for everyone, but time is money, and so we need to learn to make do with things that we consider unsatisfactory. ${ }^{47}$

In this process, the three national souls should have equal weight, although the interviewees have often remarked that the UK enjoys a heavier 'symbolic' one, while Germany seems to step back in discussions, waiting for others to agree.

In fact, the channel Sky Arts UK has a much longer history, ${ }^{48}$ a pool of subscribers which is almost twice as large as the Italian one, ${ }^{49}$ an editorial direction calibrated for British television - where art shows are few but important, also on network $\mathrm{TV}^{50}$ - and therefore aware of the necessity to stand out. Let us also think of MoP's primacy in being the only show entirely made in Italy by Italian workers and Italian writers to be broadcast on British TV:

Maybe it's also due to the fact that Germans make far fewer decisions and seldom speak their minds, but the actual struggle takes place between Italian aesthetics and British pragmatism. With the addition of some detail requested by the Germans, such as "we need another German guy". ${ }^{51}$

As confirmed by the German senior producer, 
$[T]$ he decisions about hosts, guests and candidates were made together at production meetings in Rome. We always tried to make it as European as possible, with equal candidates from each Sky Country (the UK, Ireland, Germany, Austria and Italy) and "extra" candidates from other countries like France. ${ }^{52}$

If the Germans' concern was making sure that nationalities were represented, for the British and their company policies the casting was not deemed complete if at least two equally skilled contestants with black, Asian, and minority ethnic backgrounds (BAME) were not chosen and at least a woman and a non-Caucasian judge were not appointed:

This policy seems to force reality, but in the end it is liberating. Because we are building an imagery, it is essential that the human material reflects the demographics of the channels' audiences and that it gives visibility to usually underrepresented identities. Of course, Italian society lacks the multiethnic composition of Germany and the UK, so we had to find an agreement on this as well. But in the end, this mediation gave the show an international scope. ${ }^{53}$

\section{Cross-Cultural Adjustments in the Creative Room}

If MoP's format had been adapted in each of the countries involved in its coproduction, the resulting versions would have likely been quite different. Specific formal and stylistic elements have more than others been the object of controversy among the project's creators, especially between the Italians and the British. Some of these include the choice of a particular narrative formula, which the Italians interviewed have labelled 'British-style', the close control on the emotional temperature of the show, the realistic approach that avoids, or at least limits, the dramatization of the contestants' stories, and lastly the identification of themes for each task. ${ }^{54}$

The first aspect, that is the narrative model, is explained well by the CEO of B/Arts:

Italians enjoy going to a restaurant, having the waiter describe each dish, and then decide whether to order steak or fish depending on his facial expression. The British read the menu from outside the establishment, and if it's not there, there's a chance they won't even walk in. The same goes with storytelling: if you don't have an initial statement, a British show will not work. You have to explain everything within the first two minutes, uncover details that will be shown at the end, and expose how the narrative will be structured, otherwise the British viewers won't get caught up. Conversely, Italians feel like they have already seen everything and lose interest. ${ }^{55}$

This is a great difference which has led to substantial changes during the editing process, proving that it is difficult to negotiate such an essential stylistic element.

Among the other examples gathered during the interviews, I would like to point out the attention to keeping the show's emotional temperature low, contradicting the usual rules of the talent show, where the task serves as a means to increase competitiveness among contestants and expectations about results, until the 'dramatic, tearful ritual'56 of the elimination:

The British view this as a problem. That's why the judges will never be able to evaluate pictures too harshly or say the words 'you are eliminated'. The judges can't even tell the contestant 'this is the worst picture', but rather tend to use more delicate phrases, such as 'this is the least successful picture'. This speaks volumes about Anglo-Saxons and their fixations. ${ }^{57}$

It is interesting to note how research on the adaptations of British talent shows, as opposed to those from other countries, highlights opposite dynamics in dramatic construction and the judges' emotional response. If we consider Pop Idol and the role of judge Simon Cowell, research has shown that his harsh comments were deemed 
unacceptable for the Asian versions of the format, in which the jury had taken on a 'much more polite' attitude, following 'local customs and traditions' ${ }^{58}$ Looking at the case of Masterchef, on the other hand, it has been noted how, despite keeping their authority and competence, judges were more low-key than in the US or Australian versions, and embodied the stereotypical cultural value of 'emotional reserve'59 associated with British culture.

A compromise among the differing visions is sought right until the recording time, when

writers meet with the networks and read the script together, check the main turning points, the way in which the tasks are presented, the episode's key-terms, with suggestions as to which words are to be inserted into the judges' script - such as 'masterclass' - and which ones are to be avoided - the British, for instance, can't stand the word 'challenge'. It's a work that is done in close contact with the other networks, in English, and on each single word. ${ }^{60}$

This way, the judges are pushed to always express a positive opinion on the pictures that they eliminate, explaining what does not work and why. 'It's difficult to keep Oliviero Toscani within these boundaries', claims the series producer, pointing out that the famous photographer is closer to Gordon Ramsay in Hell's Kitchen than he is to the impassionate, diplomatic character seen in MoP:

The judge can't say that he doesn't like a picture without giving an explanation. This is something that other Italian talent shows treat with lightness. We have developed techniques that allow the judges to say things that the British thought were important, without directing them or their choices, which is instead the case in most talent shows, Masterchef included. ${ }^{61}$

The British partners' need to control the judges' communication style has prompted the Italian authors to find ways to interact with them without losing the authenticity of their intentions.

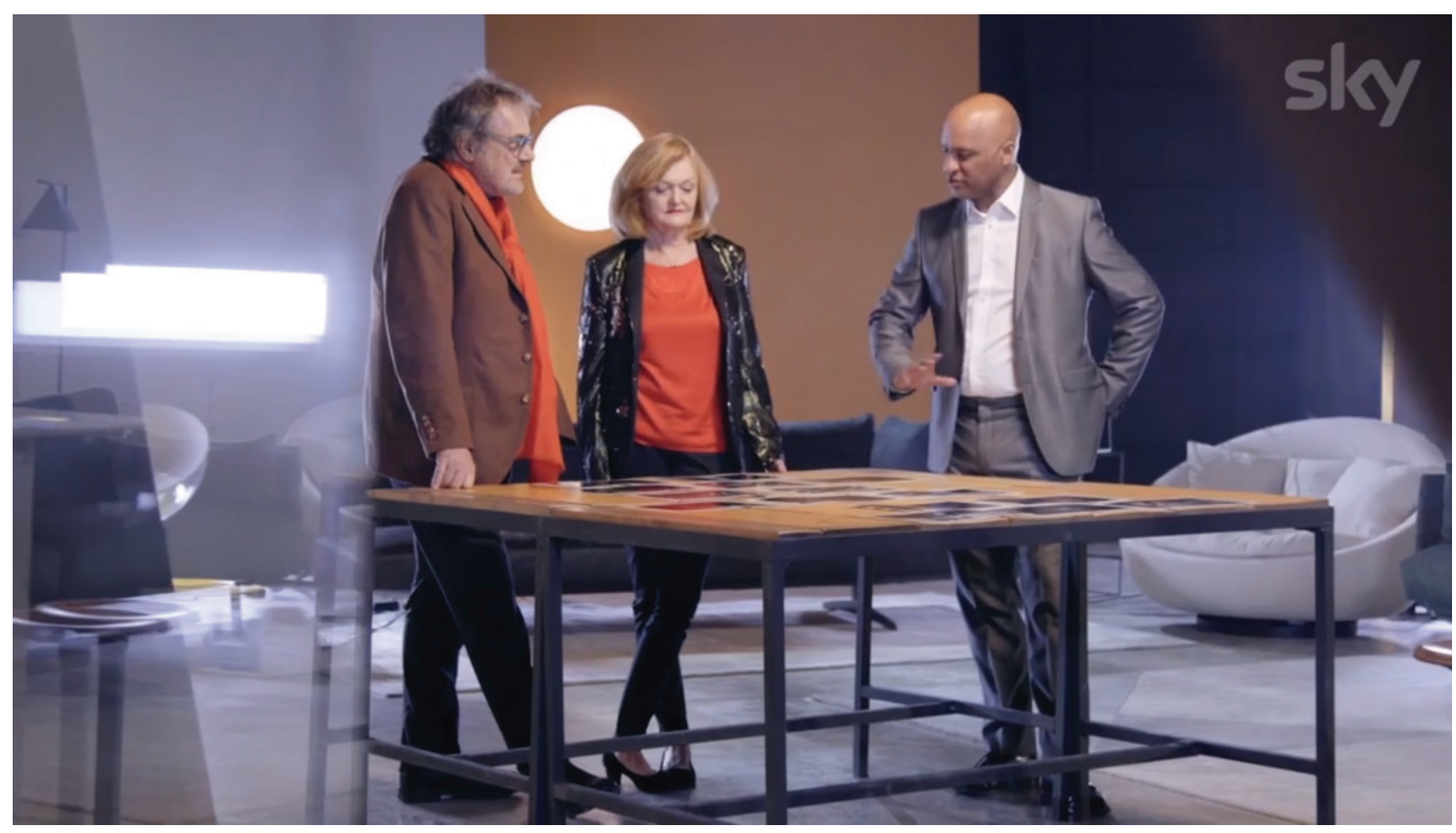

Figure 6. Frame from episode 'Sanctuary,' 3: 8. 
A third clash that has required mediation is due to the fact that the British privilege realistic situations, with little emphasis on characters, rather than the dramatic charge of talent shows beloved by the Italian public:62 "The Italianstyle talent show rests upon the stories of the contestants, while the British don't appreciate the confessional, ${ }^{63}$ which is an element that we've had to give up on", ${ }^{64}$ also due to the contestants' restrained personalities. Consequently, instead of diving deep into the personal backgrounds of the contestants and of building dynamics based on their most distinctive character traits and rivalries, ${ }^{65}$ the resulting narrative focuses on the subjects of the tasks: the importance of the themes proposed allows the contestants to narrate the pasts of the people and places photographed.

Alongside classical architectural masterpieces, season after season, the photographers have been asked to show the hidden sides of famous places, such as Rome's multicultural Torpignattara neighbourhood. ${ }^{66}$ They photographed transgender people, Paralympic athletes, women in traditionally male positions of power, celebrity look-alikes, as well as unconventional subjects, such as working animals - dogs helping firefighters rescue people from the rubble, or donkeys doing pet therapy. For each of these themes there were viewpoints connected to the features and sensibility of each nationality:

There are countries where you can be sued if you show animals in captivity, and others where this is not a concern. In the episode on transgenders we walked on eggshells so as not to hurt anyone's feelings. And even when we wanted to joke a little on something, the British would send us notes saying 'this kind of humour is not funny to us'. Television is one of the elements that shapes, accompanies, and reflects the culture of a country, and during this project we have seen this extensively. ${ }^{67}$

Regarding this aspect, it bears pointing out that the game of mirrors between a culture and its TV representation was not particularly effective for the Italian public. Despite meeting Sky Arte's goals, the Italian reception of this show was lukewarm, unlike in the UK, where viewers' engagement was more than satisfactory. ${ }^{68}$ The Italian public has possibly suffered from cultural and linguistic distance, something increased especially by the use of re-voicing which, despite lending greater realism to the dubbing by keeping the original voices and tones available in the background with a slight delay, paradoxically assimilates the program to the majority of ready-made factual documentaries:

When you watch MoP, you do not get the feeling that it is an Italian show, because it isn't. It's a show that's conceived to be international, and therefore what it does tell you about Italy is only visible in three aspects: the Italian contestants, the presence of Toscani, and the locations, which for production reasons are almost entirely Italian. ${ }^{69}$

But perhaps this was not enough for the Italian public to become fully involved.

\section{Conclusions}

According to one of the key-people interviewed for this research, MoP, the ready-made show produced in Italy by SAPH and B/Arts for the Sky Arts channels of five European countries, and destined to the wider distribution arm Sky Vision, ${ }^{70}$ is 'what the Greeks would have defined a hapax, a word or a phrase that only occurs once within a work', more precisely, within the work of an artist or within the entire literary production in a given language.

Through interviews to professionals involved in every stage of the production on the Italian side, and through a careful analysis of the narrative structure and stylistic aspects of the show, this research has highlighted its uniqueness. The analysis has also brought attention to a certain resistance to change displayed by some Italian production modes. None of the interviewees failed to mention how, despite positive personal and professional aspects, this creative collaboration was difficult, elaborate, tiring: "the problem is also having to decide, time after time, which compromises to make, with the awareness that the more one 'yields', the more the product becomes distanced from the Italian public". ${ }^{71}$ 
Additionally, the interviewees reveal that during the creative process considerable attention was paid to satisfying the expectations of the target audiences, rather than to creating a product that could travel beyond the borders of Italy, Germany, and the UK. Certainly, the coproduction has emphasized elements that could be relevant for all cultural identities involved in the project, and that could make it appealing to transnational audiences, but in this process of exchange and negotiation the British played the most decisive role in dramatic construction, where their pragmatism prevailed over the Italian aesthetic.

This was the case when opting for a narrative formula in which the opening statement briefly outlines the whole content of the episode, forcing important editing changes on the planning and elaboration of the opening segments. This was also the case when dealing with the emotional aspect of the show, which resulted in the loss of pre-eminence of the contestants' personal stories in favour of a focus on the photographic process and the contents of each task. Lastly, the same phenomenon shaped the role of the jury - always a strong localizing factor in worldwide talent shows - which, in this program, was devised to be specialized and understandable, authentic and believable, but also representative of different cultural sentitivities, because "what is defined as authority varies from culture to culture". ${ }^{72}$ Even without stressing the individual judges' identities, a jury comprising professionals with different nationalities and backgrounds offered the viewers a varied range of entry points to the experience.

As far as Italy is concerned, the strategic value of $M o P$ is its having been the test bench for an innovative, original creative and production process - one never tried before and never replicated after - even despite the lengthy times required by the coordination of all national parties, growing budget cuts and quality expectations for the product. ${ }^{73}$ The high aesthetic quality of cinematography, sound and direction, which are the central elements of the Italian television style, was highly appreciated by the British and the Germans - "our aesthetic competence has often surprised our international partners" 74 - becoming one of the main strengths of the Italian production in the overall creative process. MoP recently won the Royal Television Society Award in the category 'Crafts and Design - Multicamera Work' and has managed to fascinate those who work in television, becoming "one of the favourites among cameramen, directors of photography, directors, writers - to the point that those who don't work on it say that they would like to". ${ }^{75}$

Lastly, this coproduction's transnational collaboration gave birth to a show that was able to widen the horizons of a now classic TV genre: "sharing ideas about producing television will result in common production practices, values and standards, and in the end this can be expected to reflect in the techniques used and in the overall style of TV programmes". ${ }^{76}$ In fact, MoP is a docu-talent show, enriched with a strong educational ambition, where attention to style has left the narrative engine almost completely unaffected and adhering to the "basic skilled-challengejudgement-elimination engine". ${ }^{77}$ Educational and documentary elements, however, do find a space in the show, also thanks to B/Arts' experience in the production of art documentary series: "MoP teaches the viewers how to have an artistic taste, or rather an interpretive taste regarding an art form. Today, this is unpopular because TV education has been replaced by the tutorial mania. But we did it regardless". ${ }^{78}$

This research cannot accurately measure the consequences of an experience of creative coproduction on the development of the production and distribution of Italian ready-mades in the world. Certainly, the establishment of transnational goals and the possibility, for an English-speaking Italian innovative show to be presented by televisions across Europe and the world have allowed B/Arts and the creators of this show to experiment with a different production model, one that has had positive effects on the company's international reputation and on the personal growth of professionals involved. Thanks to the production's constant reporting, each writer, filmmaker, and producer involved was able to break down their contribution within the process and to distinguish it, thus gaining awareness as to how much their work depends on previous decisions and influences in subsequent phases. This was an exercise in mediating and understanding the aesthetic sensitivities of international partners: an experience which is rare in national productions and that is even more limited when adapting a global format to local contexts. 


\section{Notes}

1. FRAPA, The FRAPA Report 2009. TV Format to the World. FRAPA. 2009. The FRAPA Report 2009: TV Formats to the World. Cologne, 63.

2. Research conducted by Ce.R.T.A. (Centro di Ricerca sulla Televisione e gli Audiovisivi of the Catholic University in Milan) with the aim to understand the strengths and weaknesses of national television entertainment production.

3. Among Italian independent TV production companies, the main ones, EndemolShine Italy, Banijay, and FermantleMedia, are part of international groups. Moreover, since its inception in 2003, Sky has played a key role as the only pay TV in the nation, re-shaping the power balance within Italian TV and reaching a position of equal relevance to the two historically dominant broadcasters, the public RAI and its private free-to-air competitor Mediaset.

4. Massimo Scaglioni, "Distratta Italia, [Forgetful Italy]" Link. Idee per la televisione. Distretti produttivi emergenti 21, (2017): 239, https://www.linkideeperlatv.it/intrattenimento-in-italia/

5. Ibid.

6. Ibid.

7. Francesco Morstabilini, "Intervista a Jan Salling. Come si crea un format che può circolare nel mondo" [Interview to Jan Salling. How to create a format that can circulate around the world], Link. Idee per la televisione. Distretti produttivi emergent 21, (2017): 73, https://www.linkideeperlatv.it/intervista-jan-salling/

8. B/Arts (Ballandi Arts) was born in 2012 as the documentary division of Ballandi Multimedia, a production company specializing in entertainment and big TV events. It became an autonomous company in 2016 thanks to Bibi Ballandi (entrepreneur, producer, and founder of his namesake company) and Mario Paloschi, with the aim to produce cultural programs and 'the mission to enhance and promote culture in the widest sense and the Italian patrimony through a strongly international narrative approach'. In 2018, after Bibi Ballandi's death, the two companies have merged again to form a joint company, Ballandi, under the leadership of the 'veteran producer' Mario Paloschi.

9. Launched in Milan in 2015, the SAPH is led by Roberto Pisoni, also head of Sky Arte (Italy). Building on Sky's long-standing strategy to bring together pay TV operators from strategic European markets, this overlapping of roles bears witness to the platform's willingness to make Italy the center of production companies interested in the creation of quality contents for the group's art channels, complementing the works produced and broadcast in each country: Sky Arts UK \& Ireland, Sky Arts Germany \& Austria, and Sky Arte Italia.

10. Michele Hilmes, "Transnational TV: What Do We Mean by ‘Coproduction' Anymore?," Media Industries Journal 1, no. 2 (2014): 11.

11. See Albert Moran, ed., TV Formats Worldwide. Localizing Global Programs (Bristol and Chicago: Intellect, 2009); Tasha Oren and Sharon Shahaf, eds., Global Television Formats: Understanding Television Across Borders (New York and London: Routledge, 2012); Jean K. Chalaby, The Format Age: Television's Entertainment Revolution (Cambridge \& Malden: Polity Press, 2015); Karina Aveyard, Pia Majbritt Jensen, and Albert Moran, eds., New Patterns in Global Television Formats (Bristol and Chicago: Intellect, 2016).

12. See Paul Torre, "Television Formats and the United States: New Developments in Production and Distribution," International Journal of Digital Television 8, no. 1 (2017): 117-41.

13. See Pia Majbritt Jensen, "How Media System Rather Than Culture Determines National Variation: Danish Idols and Australian Idol Compared," in Adapting Idols: Authenticity, Identity and Performance in a Global Television Format, eds. Koos Zwaan and Joost de Bruin (London and New York: Routledge, 2012), 27.

14. Matthew Smith and Andrew Wood, eds., Survivor Lessons: Essays on Communication and Reality Television (Jefferson, NC: McFarland, 2003).

15. Ernest Mathijs and Janet Jones, eds., Big Brother International: Formats, Critics and Publics (New York: Wallflower Press, 2004).

16. Anne Cooper-Chen, "A World of 'Millionaires': Global, Local and 'Glocal' TV Game Shows," in Global Entertainment Media: Content, Audiences, Issues, ed. Anne Cooper-Chen (Hillsdale, NJ: Lawrence Erlbaum Associates, 2005), 237-51; Lauhona Ganguly, "Global Television Formats and the Political Economy of Cultural Adaptation: Who Wants to Be a Millionaire? in India," in Global Television Formats: Understanding Television Across Borders, eds. Tasha Oren and Sharon Shahaf (New York and London: Routledge, 2012), 323-45.

17. Koos Zwaan and Joost de Bruin, eds., Adapting Idols: Authenticity, Identity and Performance in a Global Television Format (London and New York: Routledge, 2012); Lauhona Ganguly, "Global Television Formats and Their Impact on Production Cultures: The Remaking of Music Entertainment Television in India," Television \& New Media 20, no. 1 (2019): 20-35.

18. Tasha Oren, "On the Line: Format, Cooking and Competition as Television Values," Critical Studies in Television 8 , no. 2 (2013): 20-35.

19. Janet McCabe and Kim Akass, eds., TV's Betty Goes Global. From Telenovela to International Brand (London and New York: I. B. Tauris, 2012).

20. Jolien van Keulen, "Aesthetic Proximity: The Role of Stylistic Programme Elements in Format Localisation," VIEW Journal of European Television History and Culture 5, no. 9 (2016): 96. 
21. Kaarle Nordenstreng and Tapio Varis, "Television Traffic, a One Way Street? A Survey and Analysis of the International Flow of Television Programme Material," Reports and Papers on Mass Communication 70 (Paris: Unesco, 1974).

22. Daniël Biltereyst and Philippe Meers, "The International Telenovela Debate and the Contra-flow Argument: A Reappraisal," Media, Culture \& Society 22, no. 4 (2000): 393-413; Andrea Esser, "Audiovisual Content in Europe: Transnationalization and Approximation," Journal of Contemporary European Studies 15, no. 2 (2007): 163-84; Timothy Havens, Global Television Marketplace (London: BFI, 2006); Daniel Mato, "The Transnationalization of the Telenovela Industry, Territorial References, and the Production of Markets and Representations of Transnational Identities," Television \& New Media 6, no. 4 (2005): $423-44$.

23. Hilmes, "Transnational TV", 11.

24. Think of the international success of Bron/Broen (The Bridge, 2011-2018), the Danish original, and the lukewarm reception of its remakes (The Bridge for the US and Mexico; The Tunnel for the UK and France, 2013). See Annette Hill, "Push-Pull Dynamics: Producer and Audience Practices for Television Drama Format The Bridge," Television \& New Media 17, no. 8 (2016): 760.

25. Ib Bondebjerg, Eva Novrup Redvall, Rasmus Helles, Signe Sophus Lai, Henrik Søndergaard, and Cecilie Astrupgaard, Transnational European Television Drama. Production, Genres and Audiences (London: Palgrave Macmillan, 2017 ), 251.

26. Hilmes, "Transnational TV", 12.

27. In 2019 the director of MoP, Giuseppe Bianchi, won the coveted award of the Royal Television Society Award in the category 'Crafts and Design - Multicamera Work'.

28. 150,000 euros in the first season, 100,000 euros in the following ones.

29. MoP has hosted many guests: in the latest season alone, Paolo Pellegrin, Martin Schoeller, Brenda Ann Kenneally, Jérôme Sessini, Chris Buck and Rankin. In previous seasons, international stars Sebastião Salgado and Steve McCurry were also guests.

30. From 2016 to today, only Toscani was a regular in all four seasons. In the first season, he was joined by Simon Frederick and Rut Blees Luxemburg, and by Caroline Hunter and Darcy Padilla in the second one. The first season had Isabella Rossellini as the presenter, but her role was removed from the format starting from the second season.

31. Roberto Pisoni, Interview with author, July 8, 2019.

32. Davide Corallo (series producer), Interview with author, July 5, 2019.

33. As Bourdon remarks in his reconstruction of the efforts to cultivate European identity through television, the experiments concerning pan-European entertainment shows are very few. Among these, besides the Eurovision Song Contest, we need to mention the famous Jeux Sans Frontières, a competition among teams from different European countries, which aired in Eurovision for several editions starting in 1965. See Jérôme Bourdon, "Unhappy Engineers of the European Soul. The EBU and the Woes of Pan-European Television," The International Communication Gazette 69, no. 3 (2007): 263-80.

34. Mario Paloschi (CEO of B/Arts), Interview with author, July 12, 2019.

35. Pisoni, Interview.

36. Among the examples of this experimentation are the choice of a presenter or a narrating voice-over, of a genre (the talent show highlighting the artists), or of a recognizable narrative style (Carlo Lucarelli's noir biographies, such as in Muse inquietanti).

37. Paloschi, Interview.

38. Corallo, Interview.

39. Ibid.

40. Barbara Frigerio (showrunner SAPH), Interview with author, October 25, 2019.

41. Paloschi, Interview.

42. Ibid.

43. Ibid.

44. Scaglioni, "Distratta Italia", 239.

45. Paloschi, Interview.

46. Ibid.

47. Ibid.

48. Sky Arts in the UK (originally, Artsworld) was born in 2000, Sky Arte in Italy in 2012, and Sky Arts in Germany was launched in 2015 as an on demand service, becoming a linear TV channel the following year. In 2019, it went back to being an on demand service.

49. In late 2018, after Sky Limited was acquired by Comcast, the pay TV subscribers in the UK were roughly 9,54 million (source: https://www.theguardian.com/media/2018/dec/23/netflix-to-overtake-sky-satelite-tv-subscriptions-by-end-of-year), excluding the approximately 1,5 millions subscribers of the streaming platform NowTV. At the end of the year, Sky Italia counted over 5 million subscribers (source: https://www.milanofinanza.it/news/sky-italia-sfonda-la-soglia-dei-5-milioni-di-abbonati-e-trascina-ilgruppo-201901242108026140).

50. In 2014, just one year before the launch of the SAPH, "Sky declared a new era of growth for Sky Arts, facilitated by a budget increase and better placement on the electronic programme guide". However, as the Ofcom data presented in the article reveal, "art television is a genre 'at risk' of disappearing, as relatively small audiences are unable to offset production costs". See Caitriona Noonan and Amy Genders, "Breaking the Generic Mould? Grayson Perry, Channel 4 and the Production of British Arts Television," Critical Studies in Television: The International Journal of Television Studies 13, no. 1 (2018): 80.

51. Paloschi, Interview.

52. Matthias Emmerich (senior producer Sky Deutschland [3rd Season]), Interview with author, August 16, 2019. 
53. Margherita Principe (executive producer SAPH), Interview with author, October 11, 2019.

54. Ostensibly, these evaluations suffer from the fact that the sample of interviewees is almost completely circumscribed within Italian borders, but it was impossible to reach out to people connected to the British channel.

55. Paloschi, Interview.

56. Guy Redden, "Making over the talent show," in Exposing Lifestyle Television: The Big Reveal, ed. Gareth Palmer (Aldershot: Ashgate, 2008), 137.

57. Corallo, Interview.

58. Sukhpreet Singh and Martin Kretschmer, "Strategic Behaviour in the International Exploitation of TV Formats: A Case Study of the Idols Format," in Adapting Idols: Authenticity, Identity and Performance in a Global Television Format, eds. Koos Zwaan and Joost de Bruin (Ashgate: Farnham, 2012), 21.

59. Louann Haarman, "MasterChef. Cooking Competition across Cultures," in Values and Choices in Television Discourse. A View from Both Sides of the Screen, eds. Roberta Piazza, Louann Haarman, and Anne Caborn (London: Palgrave Macmillan, 2015$), 179$.

60. Fabrizio Guiducci (senior reporter), Interview with author, April 10, 2019.

61. Corallo, Interview.

62. "Italians want more carnage. They want to see blood flow!," Ibid.

63. The confessional is the tool through which details of the lives of the show's protagonists are revealed.

64. Pisoni, Interview.

65. There is only one episode in the format ('Home Sweet Home') in which the contestants talk about themselves: the last three photographers still in the game go back home to photograph the place from which they come and make a self-portrait.

66. The majority of these tasks takes place in Italy, because the budget allowing contestants to travel across Europe is ever shrinking. On the one hand, this is an instance of the negotiations among different parts of the production chain highlighted by many interviewees. On the other hand, however, this provides an occasion to show the country in a way which few were familiar with.

67. Corallo, Interview.

68. Essentially, these are the remarks that emerged during the exchanges with Sky stakeholders, based on proprietary qualitative studies. Ratings are not available because the Sky Arts channels have no rating measurement.

69. Corallo, Interview.

70. Today folded into NBC Universal's Global Distribution unit following Comcast's $\$ 39$ billion purchase of Sky Limited.

71. Pisoni, Interview.

72. Karen Ross and Doug Wood, "Competition and Cookery in a Global Cultural Format," in Values and Choices in Television Discourse. A View from Both Sides of the Screen, eds. Roberta Piazza, Louann Haarman, and Anne Caborn (London: Palgrave Macmillan, 2015), 226.

73. Many interviewees remark about the systematic budget shrinkage from one season to the next.

74. Paloschi, Interview.

75. Manuela Calabrò (production supervisor), Interview with author, April 18, 2019.

76. van Keulen, "Aesthetic Proximity", 97.

77. Tasha Oren, "On the Line", 28.

78. Corallo, Interview.

\section{Biography}

Marta Perrotta $(\mathrm{PhD})$ is associate professor at Roma Tre University, Italy, where she teaches two courses (Digital media and Cultures and formats of Radio and Television) and the Tv Format Writing workshop. Her main research interests include comparative television studies, production studies, radio and sound studies. She is author of three manuscripts - Fare Radio (2017), II Format Televisivo (2007) and L'ABC del fare radio (2003) - and co-editor of Factual, Reality, Makeover (2013), with Veronica Innocenti. Her articles and papers appear in journals like Media Culture and Society, The Radio Journal, Problemi dell'Informazione, International Journal of Cultural Studies, Imago. She has been working as writer, editor and author with radio and TV production companies and broadcasters. She is the programming director of the college radio station Roma Tre Radio (radio.uniroma3.it). 